\title{
Controlling Choice: Teachers, Students, and Manipulatives in Mathematics Classrooms
}

This research study examines the instructional practices of 10 middle grades teachers related to their use of manipulatives in teaching mathematics and their control of mathematics tools during instruction. Through 40 observations of teaching, 30 interviews, and an examination of 67 written documents (including teachers' plans and records), profiles were developed that describe how teachers used and controlled manipulatives during instruction. Results showed that teachers used a variety of manipulatives and other mathematics tools over the course of the year-long study. Teachers reported using a mathematics tool (manipulative, calculator, or measuring device) in $70 \%$ of their lessons, and this self-report was verified by observations in which teachers used mathematics tools in 68\% of their lessons. During a 3-to 4-month period of "free access," in which students had some measure of control in their selection and use of the mathematics tools, the students used manipulatives spontaneously and selectively. During free access, teachers exhibited various behaviors, including posting lists of items on containers, assigning group leaders to manage tools, and negotiating the control of the mathematics tools during instruction.

Manipulative use in today's mathematics classrooms is taken for granted. Yet using manipulatives effectively to engage students in meaningful experiences that promote mathematical understanding is a function of the tasks for which a teacher conceives them being used (Moyer, 2001). Manipulatives are designed to represent explicitly and concretely abstract mathematical ideas. Research on their use has shown that students who use manipulatives during learning outperform those who do not (Driscoll, 1983; Greabell, 1978; Raphael \& Wahlstrom, 1989; Sowell, 1989; Suydam, 1985, 1986). Some studies show that student achievement levels are related to teachers' experience in using the manipulatives (Raphael \& Wahlstrom, 1989; Sowell, 1989). Although much of this research documents manipulative use in prescribed teaching and learning interactions (Parham, 1983), few reports tell us how teachers use the manipulatives (Moyer, 2001), nor do they describe how students use manipulatives when they are given a choice to do so.

The purpose of this research study was to investigate ways teachers and students used manipulatives during mathematics instruction and the nature of those interactions when the environment was altered to give students "free access," or a choice of when and how to use the manipulatives. Although the National Council of Teachers of Mathematics (NCTM, 2000) standards have heightened teachers' awareness of the use of mathematics tools for instruction, the subtleties of how to use them effectively or how students might use them are still not clearly understood. In the current climate of mathematics reform, this study serves the important role of highlighting new interaction patterns in mathematics classrooms by examining the dynamic of shared control by sharing the tools of mathematics learning. In doing so, it provides a glimpse of how teachers and students struggle with the process of shifting their roles in mathematics classrooms under these conditions.

Although we were interested in the whole context of the classroom interactions, the primary lens of observation in this paper is on the teachers and their uses of manipulatives, with a secondary lens focused on how students used manipulatives in relationship to the teachers' instruction. We have framed these interactions by describing them in terms of the "sets" - that is, the mathematics classroom environment, the "scripts" - that is, what the individuals in that environment say and do, and the "roles" - that is, the way in which individuals perceive the part they play in these interactions. The results focus directly on precise uses of 
manipulatives by teachers, particularly when students are given choice in the use of these materials and, as a result, produce important evidence about teachers' control of mathematics tools and students' spontaneous uses of those tools to mediate their own learning.

\section{The Mathematics Classroom: Shifting Control}

Teachers' views regarding manipulative use are situated in their own assumptions about and experiences in mathematics and schooling. Research in mathematics education and cognitive psychology encourages educators to shift from the memorization of facts and algorithms toward instruction that involves students in mathematical concept construction (Cobb, 1994; Cobb, Yackel, \& Wood, 1992; Peterson, Fennema, \& Carpenter, 1989). An emphasis on computation, procedures, rules, and algorithms, differs dramatically from current theories of cognition and the Principles and Standards for School Mathematics (NCTM, 2000).

Sharing choice in the mathematics classroom implies that teachers must give up some of their control of the learning to students, thereby shifting their established roles as "experts." The level of choice students are permitted in their mathematics classrooms is directly related to the amount of control teachers exert in that environment. Research shows that teachers exert different control orientations in classroom settings (Deci, Spiegel, Ryan, Koestner, \& Kauffman, 1982) through a variety of instructional behaviors, such as giving students choice and giving students praise. For example, Deci et al. (1982) found that control-oriented teachers

1. Talk twice as much as their more autonomyoriented counterparts.

2. Allow students to work alone much less.

3. Give three times as many directives.

4. Make three times as many "should" statements.

5. Ask twice as many controlling questions.

6. Make two and a half times as many criticisms. 1982).

7. Give students much less choice (Deci et al.,

Control-oriented teachers are also more likely to praise or criticize students' performance, give deadline statements, and provide hints, leading statements, or solutions. Studies have shown that if teachers are control-oriented the controlling aspects of their rewards or communications will likely be particularly salient, overshadowing and undermining children's intrinsic motivation and perceived competence (Deci \& Ryan, 1987; Deci, Schwartz, Sheinman, \& Ryan, 1981).

Autonomy-oriented teachers, on the other hand, are more likely to provide their students with a choice.
They are less likely to criticize or to communicate with directives, such as "should" and "put," and deadline statements. Overall, they talk less in instructional situations than do their control-oriented counterparts (Deci \& Ryan, 1987; Deci et al., 1981). In the mathematics classroom, a teacher who promotes intellectual autonomy encourages students to be active participants in the classroom community and to draw on their own capabilities when making mathematical judgments and decisions (Yackel \& Cobb, 1996).

Teachers' roles are critical in negotiating and establishing the quality of classroom interactions. Students' construction of knowledge is based on their experiences in those interactions in which students determine how and what mathematical knowledge is constructed (Cobb \& Steffe, 1983). Ideally, in the $21^{\text {st }}$ century mathematics classroom, control of mathematics tools and decisions to use them should be shared within a guided framework. However, accessing these tools is often claimed solely as the teacher's domain. Previous research has found that students are able to selectively use mathematical tools effectively while learning. In research on the use of calculators, Hirschhorn and Senk (1992) found that students given free access to calculators overused these tools initially and moved to more appropriate use over time.

The concept of autonomy connotes an inner endorsement of one's own actions or choices. Intellectually autonomous students make decisions to initiate and regulate their own behavior, selecting desired outcomes and choosing how to achieve them (Deci \& Ryan, 1987). Students who are given the autonomy to use manipulatives would, therefore, have the opportunity to initiate and regulate their own mathematical decisions, judgments, and behaviors, thereby exercising some control over the experiences they have that determine what mathematics they construct and how.

The learning of mathematics, like learning in other school contexts, does not take place without the negotiation of control. An examination of teachers' and students' uses of manipulatives in typical classrooms can provide insight into how manipulatives play a role in the negotiation of that control. This study investigated the following research questions:

1. How do teachers and students use mathematics tools during instruction?

2. What is the effect on their interactions when the mathematics environment is altered by giving students free access to the mathematics tools?

The answers to these questions are described in terms of shifts in the mathematics environment and what teachers and students say and do in that environment. 


\section{Methods}

\section{Participants}

Participants in this research study were drawn from a pool of 18 teachers, all female, enrolled in a summer mathematics institute. All of the teachers volunteered to participate in the study. Teachers were selected from this summer institute to ensure that they all had access to the same sets of mathematics tools (which they received during the institute) and that they all participated in the same professional development related to the use of those mathematics tools. On the first day of the institute, teachers completed the Problems in Schools Questionnaire (PSQ, Deci et al., 1981), and 10 of the 18 middle-grades mathematics teachers were selected based on their scores on the PSQ. The 5 teachers with the highest scale scores and the 5 teachers with the lowest scale scores were selected for the purpose of determining whether a teacher's control orientation would impact the way the teacher allowed students to use mathematics tools. The other 8 teachers who had scores in the mid-range on the PSQ were dropped from further participation in the study. During the summer session and an initial interview, background information on each teacher was collected, including years of teaching experience and their use of manipulatives from the previous school year.

\section{Instrument}

The PSQ (Deci et al., 1981) is a 32-item survey that reflects teachers' orientations toward control or autonomy, with a higher scale score reflecting a more autonomous orientation and a lower scale score reflecting a more controlling orientation. The PSQ contains eight vignettes, each followed by four items (or subscales) that represent four different behavioral response options. Respondents rate the appropriateness of each of the four options on a 7-point Likert-type scale. Each of these subscales allows the teacher to select from a range of 1 to 7 , giving a total of 32 ratings.

Deci et al.'s (1981) research of this instrument reported that teachers will vary considerably in their orientations toward control and autonomy. Deci et al.'s analysis of this instrument with teachers reported most scores between 2.13 and 12.13, with one extreme score of -10.13 . Deci reported the effective range of the data on this instrument to be 10, although the actual range was 22.25. Scores between 2.13 and 12.13 were normally distributed, with a mean of $6.98(S D=3.11)$. Studies were conducted with teachers to determine the instrument's validity (Deci et al., 1981; Reeve, Bolt, \& Cai, 1999). A correlation of teachers' scores and their students' perceptions of classroom climate resulted in a score of .35 , significant at the .05 level. The test-retest reliability coefficients for the four subscales ranged from .77 to .82 , and the test-retest reliability of the total scale was .70. The test of internal consistency on the 32 correlations showed scores from .40 to .80 . Correlations of items with their total subscales range from .53 to .64. The values of Cronbach's alpha for standardized scores for the four subscales were .73, .71, .63, and .80; for nonstandardized scores, the alpha were $.70, .69, .63$, and .76, showing good internal consistency.

\section{Procedures}

The qualitative data for this study included transcriptions from 40 classroom observations, 30 teacher interviews, and 67 teacher-written documents. Data were gathered during two phases of instruction in the 10 middle grades mathematics teachers' classrooms for a period of approximately one academic year. During Phase 1 (August-November), researchers observed teachers using manipulatives for mathematics instruction. During Phase 2 (November-March), teachers were asked to provide students with "free access" to manipulatives in containers on students' desks.

Summer institute. The 10 teachers in the study participated in a summer mathematics institute, where they discussed methods of using various representations for teaching mathematics with conceptual understanding. The 2-week summer institute included a variety of experiences in teaching mathematics that helped develop conceptual understanding, procedural fluency, adaptive reasoning, and strategic competence (as defined in National Research Council, 2001). Teachers participated in interactive sessions focusing on classroom dialog, effective manipulative use strategies, and various forms of representations. There were opportunities to identify mathematics representations appropriate for specific mathematics content, and manipulatives were used to explore abstract mathematics concepts. Manipulative use was introduced as one of several pedagogical tools for teaching mathematics in the middle grades.

During the summer institute, teachers received a mathematics manipulatives kit and learned how to use manipulatives, measuring tools, calculators, and computers for teaching and learning middle grades mathematics. The kit included one set of base-10 blocks, one set of six tripour beakers, one set of color tiles, one set of 1,000 snap cubes, one set of 10 geometric solids, 15 geoboards with rubber bands, three sets of dice, three sets of pattern blocks, one rocker scale, 30 hundreds boards, six sets of fraction bars, one 
set of 10 thermometers, one trundle wheel, 15 centimeter and inch tapes, seven sets of tangrams, three mirrors, 15 triman protractors, and 15 triman compasses. Additionally, all teachers had calculators and teachermade mathematics materials in their classrooms, as well as access to computers at their schools.

Pre-assessment phase. In early September, each teacher participated in an audiotaped, semistructured 45-minute interview. The purpose of the interview was to identify background information on teachers' uses of mathematics manipulatives and instructional practices. The initial protocol for this interview was developed during a pilot study. This protocol was modified for the second and third interviews on the basis of subsequent classroom observations and teacher interviews.

Phase 1. In September and October, the 10 teachers were each observed twice for a total of 20 scheduled classroom observations. Teacher and student verbal and nonverbal behavior was recorded with field notes and audiotape recordings. Each teacher was equipped with a lapel microphone and audiotape recorder to preserve the discourse during instruction. Data collected during these observations included detailed descriptions of teachers' activities, behaviors, actions, interpersonal interactions, and direct quotations, as well as descriptions of students' behaviors and comments. In the weeks following the two classroom observations, each teacher participated in a second interview.

Each month, teachers were asked to write selfreports of their mathematics instruction. To prompt these reports, a postcard was mailed to each teacher with the following request:

Tell me about the last mathematics lesson you taught. We realize the lesson may or may not be representative of a typical lesson in your classroom. We realize the lesson may or may not have used manipulatives. Please include any plans or worksheets you used with this lesson.

During Phase 1 and Phase 2 seven postcard requests were mailed to each teacher, for a total of 70 requests.

Phase 2. From November through March, teachers were asked to provide students with free access to mathematics tools (including concrete manipulatives and calculators) during instruction. For the purposes of this study, free access was defined as the opportunity for students to select and use materials they identified as necessary in providing assistance in mathematical situations. Teachers were asked to provide students with a variety of manipulative materials and calculators placed in containers located on or near student desks so that students would not need to leave their seats to get the materials or ask for the teacher's permission to use the materials. In essence, students had some measure of control in their selection and use of the materials. Each classroom was observed twice during this phase, for a total of 20 scheduled observations. Following the third and fourth classroom observations, teachers participated in a third interview.

\section{Analysis}

The following data were used as sources in the analyses: 30 teachers' interviews, teachers' and students' audiotaped verbalizations and fieldnotes during 40 classroom observations, and 67 teacher-written documents in response to the postcard requests. These data were used simultaneously to examine instructional events in their situational context. Audiotapes were transcribed, and field notes and transcriptions were analyzed and coded for themes (see, e.g., LeCompte, Preissle, \& Tesch, 1993) to identify uses of manipulatives during both phases of instruction. Teachers' lesson documents provided a more holistic picture of instruction during the researchers' absence from the classrooms. During the firstreading, the researchers reviewed $100 \%$ of the observational and interview data to identify and code major categories within the transcriptions. Major themes centered around teachers' uses of manipulatives, teachers' opinions about manipulatives, teachers controlling choice, and students' spontaneous use of manipulatives.

A second reader was trained to code the data to verify accuracy. The second reader reviewed $60 \%$ of the observational and interview data to identify major themes repeated throughout the transcripts and then coded an additional $25 \%$ of the data, examining the transcriptions for specific instances related to the themes and systematically searching for discrepant data. A comparison of the second reader's and the researcher's coding of the transcriptions for instances of the themes resulted in a correlation coefficient of 0.87 , with the second reader coding fewer instances of the themes in transcriptions than the researcher. This result was obtained by computing the number of instances of agreement over the total number of instances for the first and second rater.

\section{Results}

\section{Teacher Background Characteristics}

The mean score on the PSQ for the 5 teachers identified as more control oriented (CO) was $M=0.68$ $(S D=1.88)$, and the mean score for the 5 teachers 
identified as more autonomy oriented (AO) was $M=$ $7.90(S D=2.06)$. An Analysis of Variance on the PSQ scores indicated a significant difference between control-oriented and autonomy-oriented teachers' scores, $F(1,8)=45.958, p<.001$. The results also indicated a significant interaction between the scores and time, $F(2,16)=5.178, p<.05$. Scores on the questionnaire are interpreted as follows: A higher score reflects a more autonomous orientation, and a lower or negative score refle cts a more controlling orientation. Controloriented teachers' scores during the summer institute increased after the first 2 months of school and decreased following free access. Autonomy-oriented teachers' scores during the summer institute decreased after the first 2 months of school and decreased following free access.

As a group, the AO teachers had an average of 9.6 years more teaching experience than did the $\mathrm{CO}$ teachers. Background information on the teachers is presented in Table 1.

Some of the teachers indicated they had learned about teaching mathematics with manipulatives in courses and professional development experiences, whereas, others indicated they had no professional development experience with manipulatives prior to the summer institute. For example, Andrea noted, "We had quite a few math classes and practicums where we'd learn to use manipulatives and things in the classroom." However, other teachers such as Elise noted, "In the past...we had boxes of things, but truthfully, we didn't know what they were used for." Julie attested that she "had the history of education and all those [general courses], so I really didn't have any hands-on math." The three teachers who had minimal prior experience with manipulatives (Julie, Ida, and Hannah) were autonomy oriented.

\section{Major Findings}

The sections that follow include these major findings:

1. Teachers reported using mathematics tools in $70 \%$ of their lessons on self-reports. Control-oriented teachers were observed using mathematics tools in $80 \%$ of their observed lessons, while autonomy-oriented teachers were observed using mathematics tools in only $55 \%$ of their observed lessons.

2. Teachers' opinions about manipulative use varied, including some who expressed apprehension, which translated into less use of manipulatives for instruction.

3. Teachers controlled students' use of the mathematics tools by restricting access to those tools during major portions of the lessons.

4. Students spontaneously used the mathematics tools appropriately for mathematics tasks during the free access phase.

5. Students were selective in their use of these tools and they returned to tasks with the manipulatives as a way to self-review previously taught mathematics concepts.

The results that follow are organized by presenting data from interviews, self-reports, and classroom observations about teachers' uses of mathematics tools

\section{Table 1}

Background Information on the Teachers
Group
Race
Grade
PSQ Score
Yrs. Teaching

\section{Reported}

Control Oriented

$\begin{array}{llc}\text { Brenda } & \text { AA } & 7 / 8 \\ \text { Donna } & \text { Cau } & 7 \\ \text { Elise } & \text { Cau } & 6 \\ \text { Andrea } & \text { Cau } & 7 \\ \text { Carol } & \text { Cau } & 6 \\ \text { utonomy Oriented } & & \\ \text { Georgia } & \text { Cau } & 6 \\ \text { Fran } & \text { AA } & 6 \\ \text { Julie } & \text { Cau } & 6 \\ \text { Ida } & \text { AA } & 7 \\ \text { Hannah } & \text { Cau } & 6\end{array}$

$-3.374 \mathrm{CO}$
$-1.375 \mathrm{CO}$
$-0.750 \mathrm{CO}$
$+0.625 \mathrm{CO}$
$+1.500 \mathrm{CO}$

$+5.750 \mathrm{AO}$
$+6.875 \mathrm{AO}$
$+7.000 \mathrm{AO}$
$+8.875 \mathrm{AO}$
$+11.000 \mathrm{AO}$

13

7

10

5

5

21

17

9

16

25
20-30 times per year

$1-10$ times per year

1-10 times per year

20-30 times per year

20-30 times per year

20-30 times per year 20-30 times per year

Not used

Not used

Not used

Note $. \mathrm{AA}=$ African American $; \mathrm{Cau}=$ Caucasian $; \mathrm{CO}=$ control-oriented $; \mathrm{AO}=$ autonomy-oriented . 
during instruction. The context of "sets," "scripts," and "roles" are then presented as a broad theme to explain teacher and student interactions in these classrooms. The set was identified as the mathematics classroom environment, the script as the verbalizations and behaviors of the individuals in the mathematics environment, and the role as the way in which individuals in the environment perceived the part they played in these interactions. Teacher pseudonyms used to develop profiles for the participating teachers are: Andrea, Brenda, Carol, Donna, Elise, Fran, Georgia, Hannah, Ida, and Julie. Interview and observation numbers are noted in parentheses using the letters " $\mathrm{I}$ " and "O," respectively.

\section{Postcard Response Reports}

Teachers returned 67 of the 70 (96\%) postcard response requests (see Table 2). They reported using a commercially made manipulative, calculator, or measuring device in 47 of these 67 lessons (70\%). The mathematics tools reported most often included calculators, hundreds boards, color tiles, measuring devices (i.e., tape measures and protractors), snap cubes, centimeter cubes, geoboards, and dice.

On the self-reports, both the AO and CO teachers reported that they used mathematics tools during instruction with approximately the same frequency. There was little relationship between the frequency of mathematics tool use teachers reported from the previous year (shown in Table 1) and their reported use during the year in which the study was conducted. However, all of the teachers reported that during the academic year in which the study occurred they were using commercially made manipulatives more often than they had the previous year.

\section{Classroom Observations}

Observations of teachers' classrooms corroborated the manipulative use reported in teacher interviews and postcard responses. A variety of mathematics tools were used during the 40 observed lessons. Table 3 reports commercially made manipulatives, calculators, and measuring devices used by the teachers and students during direct instruction and guided practice portions of the lessons.

When the manipulative use is examined by control orientation, $\mathrm{CO}$ teachers use mathematics tools at a rate of 16 of 20 lessons $(80 \%)$ and $\mathrm{AO}$ teachers at a rate of 11 of 20 lessons $(55 \%)$. The $\mathrm{CO}$ teachers used mathematics tools significantly more in observed lessons than did the AO teachers. Overall teachers used mathematics tools in over $67 \%$ of the lessons observed.

Table 2

Mathematics Tool Use Reported by Teachers to Monthly Postcard Requests

\begin{tabular}{|c|c|c|c|c|c|c|c|}
\hline Group & $\begin{array}{l}\text { Card } 1 \\
\text { (Sept.) }\end{array}$ & $\begin{array}{c}\text { Card } 2 \\
\text { (Oct.) }\end{array}$ & $\begin{array}{c}\text { Card } 3 \\
\text { (Nov.) }\end{array}$ & $\begin{array}{l}\text { Card } 4 \\
\text { (Dec.) }\end{array}$ & $\begin{array}{c}\text { Card } 5 \\
\text { (Jan.) }\end{array}$ & $\begin{array}{c}\text { Card } 6 \\
\text { (Feb.) }\end{array}$ & $\begin{array}{l}\text { Card } 7 \\
\text { (Mar.) }\end{array}$ \\
\hline \multicolumn{8}{|c|}{ Control Oriented } \\
\hline Brenda & $\mathrm{X}$ & $\mathrm{cm}$ cubes & $\mathrm{cm}$ cubes & snap cubes & $\mathrm{X}$ & pattern blocks & dice \\
\hline Donna & $\begin{array}{l}\text { cm cubes } \\
\text { color tiles }\end{array}$ & $\mathrm{X}$ & $\begin{array}{l}\mathrm{cm} \text { cubes } \\
\text { calculator }\end{array}$ & $\begin{array}{l}\text { 100s board } \\
\text { color tiles }\end{array}$ & cm cubes & snap cubes & geoboards \\
\hline Elise & protractor & geoboard & protractor & $\mathrm{X}$ & dice & $\mathrm{X}$ & $X$ \\
\hline Andrea & $\begin{array}{l}\text { counters } \\
\text { calculator }\end{array}$ & $\mathrm{X}$ & color tiles & snap cubes & snap cubes & $X$ & $X$ \\
\hline Carol & tangrams & $\begin{array}{c}\text { 100s board } \\
\text { dice }\end{array}$ & $\mathrm{X}$ & geoboard & $\begin{array}{l}\text { calculator } \\
\text { tape meas. }\end{array}$ & snap cubes & snap cubes \\
\hline \multicolumn{8}{|c|}{ Autonomy Oriented } \\
\hline Georgia & $\begin{array}{l}\text { 100s board } \\
\text { cm cubes }\end{array}$ & $X$ & $\mathrm{X}$ & snap cubes & $X$ & NO CARD & NO CARD \\
\hline Fran & tangrams & color tiles & base-10 blocks & color tiles & $\mathrm{X}$ & geoboards & NO CARD \\
\hline Julie & $\mathrm{X}$ & $\mathrm{X}$ & $\mathrm{X}$ & yardstick & protractor & $\mathrm{cm}$ cubes & fraction bars \\
\hline Ida & base-10 blocks & calculator & $\begin{array}{l}\text { 100s board } \\
\text { color tiles }\end{array}$ & calculator & fraction stacks & $\mathrm{X}$ & $\mathrm{X}$ \\
\hline Hannah & wood tiles & tape meas. & counters & $X$ & $\begin{array}{l}\text { 100s board } \\
\text { color tiles }\end{array}$ & 100s board & $\begin{array}{l}\text { dice } \\
\text { ruler }\end{array}$ \\
\hline
\end{tabular}

Note. "X" indicates no mathematics tool was reported during the lesson. NOCARD indicates the teacher did not send a report to the postcard request. 
Table 3

Mathematics Tool Use During Classroom Observations

\begin{tabular}{|c|c|c|c|c|}
\hline Group & Lesson 1 & Lesson 2 & Lesson 3 & Lesson 4 \\
\hline \multicolumn{5}{|l|}{ ontrol Oriented } \\
\hline Brenda & snap cubes & pattern blocks & $\begin{array}{l}\text { snap cubes, cm cubes, } \\
\text { color tiles }\end{array}$ & $\begin{array}{l}\text { snap cubes, } \\
\text { cm cubes }\end{array}$ \\
\hline Donna & $\begin{array}{c}\text { 100s boards, color tiles, } \\
\text { dice }\end{array}$ & $\mathrm{cm}$ cubes & $\mathrm{X}$ & snap cubes \\
\hline Elise & $\mathrm{X}$ & snap cubes & $\mathrm{X}$ & Dice \\
\hline Andrea & counters & X & protractor, calculator & geoboard \\
\hline $\begin{array}{l}\text { Carol } \\
\text { utonomy Oriented }\end{array}$ & calculators & calculators & color tiles, pattern blocks & pattern blocks \\
\hline Georgia & tape meas. & color tiles & geoboards & $\mathrm{X}$ \\
\hline Fran & $\mathrm{X}$ & $\mathrm{cm}$ cubes & $\mathrm{X}$ & snap cubes \\
\hline Julie & $\mathrm{X}$ & $\begin{array}{l}\text { meter stick, ruler, } \\
\text { tape meas. }\end{array}$ & tangrams, rulers & tangrams \\
\hline Ida & calculators & $\mathrm{X}$ & $\mathrm{X}$ & $X$ \\
\hline Hannah & $\begin{array}{l}\text { color tiles, } 100 \text { s boards, } \\
\text { calculators }\end{array}$ & $\mathrm{X}$ & protractors & $X$ \\
\hline
\end{tabular}

Note. "X" indicates no mathematics tool was used by the teacher during instruction.

It appeared that CO teachers worked hard to use the manipulatives during the observed lessons. Their control orientation seemed to extend into manipulative use by their efforts to show they could use the tools as they had been taught.

In 20 of the 40 observations (50\%), teachers and students used a commercially made manipulative during the mathematics class. In 4 of the 40 lessons (10\%), teachers and students used a measuring device such as a tape measure or protractor. In five of the lessons $(12.5 \%)$, teachers and students used calculators. In 13 of 40 lessons (32.5\%) no mathematics tool was used during instruction. In $65 \%$ (26 of 40) of the observed lessons students used a worksheet or textbook during part of the lesson. During two observations, students wrote multiplication facts and took a basic facts speed quiz.

Lessons were primarily teacher directed, with students using the manipulatives following teachers' instructions for the topic of the lesson. Mathematics tool use ranged from Brenda's use of a commercially made manipulative in all four of the observed lessons to Carol's use of a manipulative in two lessons and a calculator in two lessons to Ida's use of a calculator in one lesson and no use of manipulatives in any of the observed lessons. Occasionally, students played more active roles in the lessons by participating in games, solving open-ended problems, and working in groups. For example, Hannah's students played a game during the second half of one lesson using the hundreds boards and color tiles. Students used different operations to combine the numbers on the tiles to make one number and then covered that number on the hundreds boards. Brenda devoted one lesson to students investigating different open-ended problems and discussing a variety of solution strategies. Students in Elise's room worked in groups of three with two dice to investigate the probabilities of rolling sums between 2 and 12 . Students in Georgia's class used tape measures and recorded the measurements of different body parts to determine ratios.

A comparison of the frequency of the mathematics tools used during the observations and teachers' prior use of manipulatives showed a linear relationship. Teachers who reported they had not used mathematics tools prior to the study used tools an average of 2.0 times during the four observations. Teachers who reported they used mathematics tools 1-10 times per year prior to the study used tools an average of 2.5 times during the four observations. Teachers who reported they used mathematics tools 20-30 times per year prior to the study used tools an average of 3.2 times during the four observations. The amount of mathematics tool use during observations appeared to be related to teachers' prior experiences with manipulatives and may be correlated with more confidence in using manipulatives during instruction. 


\section{Teachers' Opinions About Manipulative Use}

Teachers' classroom practices and opinions about manipulative use varied by observation and interview. Table 4 shows typical comments from interviews characteristic of teachers' opinions about manipulative use.

The comments in the table by Julie, Ida, and Hannah, indicate some level of apprehension about using the manipulatives for mathematics instruction. Their reaction is not surprising because these three teachers had the least amount of experience with the manipulatives prior to instruction. The observations of the teachers revealed that Ida's and Hanna's apprehension translated into a decision not to use manipulatives during instruction (see Table 3).

The most common ways the manipulatives were used, as described by the teachers, were for demonstrations or problem solving. AO teachers also expressed concern about their inexperience with using the manipulatives. As the variety of comments show, the teachers saw the purpose of manipulatives as being a reward, a change of pace, something concrete to work with, enrichment, or just for fun.

\section{Student Free Access to Manipulatives}

Prior to the start of free access, all teachers were asked to make predictions about how they thought their students might respond to having access to the manipulatives at their desks. There were a variety of responses: "I predicted they would only use what I showed them" (Andrea, I3); "I thought girls would be less likely to use them" (Brenda, I3); "I thought the kids would just play" (Carol, I3); "I thought my class would be chaotic" (Donna, I3); and "I didn't think they would use them" (Elise, I3). Georgia was most concerned that the materials would be left on students' desks or on the floor and would become a safety hazard. Julie and Fran

\section{Table 4}

Teachers' Opinions About the Purposes and Uses of Manipulatives

\section{Group The purpose of manipulatives is...}

Control Oriented

Brenda It's a concrete way of showing them and then they can move on to not needing the manipulatives to see the pattern or the rule (I1).

Donna Just to have a change of pace in math...instead of lecturing every day, it gives some kind of break in the routine. To think that math can be fun at times instead of boring (I1).

Elise It gives them something they can see and work with other than just paper-and-pencil (I1).

Andrea If anything, it's a reward for them because there have been times when I have taken them away (I1).

Carol To help them understand the concept. To get it more concrete in their heads (I1).

Autonomy Oriented

Georgia I think it's another tool to help students solve problems, it's just like another strategy (I1).

Fran They teach real mathematics with a fun overtone (I2).

Julie Sometimes I think manipulatives are just for fun, but eventually we'll get to the real math part (I2).

Ida To enrich what they have already been taught (I1).

Hannah So students can understand the concept... I want my students to understand instead of just throwing out worksheets (I1).

\section{How I use manipulatives...}

I might demonstrate at the beginning and then let the kids do activities along the same lines as I demonstrate (I1).

Problem solving.... It makes the students learn in a different way (I1).

We have a problem-solving day on Fridays where we sometimes use them, mostly for interest (I1). Ialways demonstrate with them [manipulatives] and then I allow them [students] to use them (I2)

I use them almost all the time, as much as I can (I2).

Ileave out [onatable] the majority of the manipulatives (I2).

I use them in a demonstration and then the kids use them to solve a problem later (I1).

I tried to use them.... I haven't really understood myself how to do it (I1).

I really don't like using manipulatives that much but I know I need to (I1).

This is my first year with the manipulatives so I have to sit down and learn them myself (I1).

Note. I indicates the interview number. 
were concerned that students would play with the materials and see them as toys instead of mathematical tools, while Ida thought students would ignore the manipulatives. Hannah's main concern was that she just did not understand what she was supposed to do during the free access phase. While not all teachers expressed great concern over the implementation of free access, many anticipated that there would be a change in the familiar mathematics environment.

One of the concerns teachers repeatedly voiced was that the manipulatives would "walk away" during free access. At the beginning of the year Brenda said, "I have to keep mine put away so that they don't walk out of the room.... As you can see, I don't have them displayed. They're still in boxes" (I1). During the first half of the year teachers tended to restrict access to the materials-organizing them before class, distributing them at a predetermined point in the lesson, collecting them at the end of the lesson, and holding students accountable for any missing or damaged materials. "I make sure I check before they leave. All the pieces and everything has to be there.... Myself [sic], or a student I trust, goes up and down the rows to collect [materials] from each person" (Carol, I1).

At the beginning of free access, most teachers told their students the same things: They were "going to have a lot of manipulatives in the containers to help them every day in math" and that "they could use whatever they wanted to help them solve problems" (Carol, I3). The general rule for using the materials in the containers (as expressed by the teachers in the study) was that students were not permitted to use any of the materials during the teachers' introduction of the lesson. After initial instructions, students might remove an item from the containers, per teachers' instructions, to use during guided practice. Following guided practice, students were typically permitted to use any of the materials in the containers.

\section{The New "Set"}

We identified the "set" as the classroom environment where mathematics learning takes place. For the purposes of this study, the guidelines of free access were to provide students with access to manipulatives at their seats so they had a choice in using them spontaneously for mathematics tasks without requiring teachers' permission. Table 5 summarizes the "set" as teachers chose to define it in their individual classrooms during the months of free access.

In five of the classrooms, containers of manipulatives were placed in the center of student table groups, with four of these five being the $\mathrm{CO}$ teachers.
In Fran's classroom, all of the containers were placed on the floor against one wall of the classroom, making "free access" for her students difficult. Three of the five CO teachers (Andrea, Carol, and Donna) placed lists on the side of each container to maintain a close watch on the inventory of math tools in the containers, whereas, none of the teachers in the $\mathrm{AO}$ group did this. Typically, at the beginning of each class period, students or the teacher placed the containers (with a variety of manipulatives and often calculators) on or near student desks.

For most classrooms, the first week of free access was somewhat chaotic. Students tended to exhibit inappropriate behaviors with the manipulatives, such as building with the blocks, drawing designs with the ruler and protractor, or throwing materials from one student to another. Sometimes these inappropriate behaviors resulted in the removal of the container from that group of students for the remainder of the class period. Later, as students had daily access to the materials and the initial novelty wore off, these student behaviors declined, and students became more selective in their tool use. During interviews all of the teachers reported that, overall, giving students free access to the manipulatives in the containers had not been problematic. However, a number of them stated that this was true because they had developed clear guidelines for the use of the materials and had communicated the guidelines to students prior to free access. As one teacher stated, "As long as the ground rules are set, I don't have a problem with it [free access]" (Elise, I3). Teachers designed the set to control students' choice.

\section{The New "Script"}

We identified the "script" as what the individuals in the mathematics environment say and do. When free access was first implemented, students tended to express skepticism. Some of them thought free access was some kind of "trick" their teacher had devised; according to Donna, her students reacted, "There's a catch to this. She's not really going to let us do this" (I3). At first students were apprehensive because they were not sure when they were allowed to select the materials. Because of this initial apprehension, teachers found that students hesitated in using the manipulatives spontaneously during the first week of free access. Often students continued to ask the teacher's permission to get something out of the container. But as time passed, students realized their freedom in using the materials and obtained materials without asking permission.

Tinkering with tools. Teachers reported that during the free access phase, students increasingly used 
Table 5

Classroom Environment or "Sets" During Free Access

Group

Control Oriented

Brenda

Donna

Elise

Andrea

Carol

Autonomy Oriented

Georgia

Fran

Julie

Ida

Hannah
Student Desks

In table groups.

Desks vary between rows and table groups.

In rows.

In table groups.

Desks vary between rows and table groups.

Desks vary between rows and table groups.

In rows.

In rows.

Desks vary between rows and table groups. In table groups.

\section{Placement of Math Tools}

At the center of the table groups.

At the center of the table groups.

On the floor by student desks.

At the center of the table groups.

At the center of the table groups.

On the floor at the table groups.

Against one wall of the classroom.

On student desks.

On the floor at the table groups.

At the center of the table

groups.

\section{Other Information on Math Tools}

Lists of materials were placed on the containers.

Lists of materials were placed on the containers.

Lists of materials were placed on the containers. Directions were posted on the wall for the use of the materials.

Materials in containers were available to students all year. the manipulatives and worked with a greater variety of materials. Andrea voluntarily maintained a record of student use that reflected this trend; she reported that, initially, her students selected tools that were familiar to them-calculators, rulers and protractors-and then they moved on to using spontaneously some of the new tools-tangrams, snap cubes, pattern blocks, and hundreds boards - as time progressed. Observations and interviews with the teachers revealed that as the weeks passed students began to understand the purpose of the manipulatives in the containers and, consequently, became more selective about the tools they obtained. Students were commonly observed creating concrete representations of geometric figures using the snap cubes and tessellations using the pattern blocks. Fran explained, "After about 4 weeks, they knew that they were supposed to use them for specific activities, not just to have them on their desks" (I3).

Students' spontaneous use of manipulatives. The ways students used the materials varied greatly across the classes. Those teachers who reported having more experiences with manipulatives prior to the study also extended students' freedom to explore, giving their students more opportunities to find different uses for the tools. For example, one student removed the tangrams from the container before class began and put the pieces together to form a square (Brenda, O4). Students also took on responsibility for their need to use particular materials in certain situations. For example, during one lesson when Julie had begun to collect the geoboards, one student protested, saying, "But the geoboards would really help solve this problem" (Julie, I3), so she distributed the geoboards to the class again.

Teachers reported that students who had free time at the end of class periods often used the manipulatives to return to a game or a concept previously introduced by the teacher. For example, Donna taught a lesson in which students investigated different ways to represent the concept of one half and one fourth on the geoboards. She reported that, in subsequent class periods after the lesson, students spontaneously returned to this investigation again and again; the researcher also observed these students working independently with geoboards at the end of one lesson. In addition, teachers in the 
study reported seeing students invent their own games using the manipulatives. Following an observation of her class in which students were observed independently using the hundreds board, Carol commented that the students often created games. She added that sometimes she was not really sure how they were using the manipulatives but that they appeared to be working on mathematics. During one lesson in Ida's classroom, the teacher did not use any mathematics tools during instruction. Later in the lesson two of the students selected calculators to explore a pattern on a worksheet (O4).

During classroom visits, students were observed spontaneously using manipulatives to solve problems. Their selections were often independent of other students' choices. For instance, during an observation of Andrea's class in which students were creating graphs, one group used the snap cubes to design a bar graph before drawing it on paper, and another group used the circular protractor to create a circle graph (O3). One student in Brenda's class explained how she used the grid side of the hundreds board and the centimeter cubes to solve a problem (O3).

In few cases did students select an instructional device that proved to be inefficient, and even these instances were quickly corrected. During an observation, Fran $(\mathrm{O} 4)$ posed the "Skeleton Tower Problem," in which a tower is built using blocks in four directions: the top layer has one block; the next layer has one block below the top block as well as one block attached to each of four sides; and each layer continues in this fashion until the resulting tower looks somewhat like four staircases projecting in four directions from the center. One student began to solve the problem by selecting the pattern blocks. When he realized that this was not an appropriate choice, he returned the blocks to the container, selected the snap cubes, and went on to solve the problem.

Other examples of students independently and spontaneously using the manipulatives were found in Julie's class, where students were observed making their own selection of measuring devices. Julie gave the students a variety of things to measure and encouraged them to select an appropriate device. During this task student partners discussed which device - the ruler, the tape measure, the yardstick, or the trundle wheelwould be most appropriate for measuring the items.

Fran reported that her students used the centimeter cubes and the base- 10 rods to determine the size of each cube compared to the rods. During one lesson, Carol taught her students how to find the least common multiple using the hundreds boards and color tiles. Later when she introduced the concept of adding and subtracting fractions, several students spontaneously used the hundreds boards and the tiles to find a common denominator. Ida reported that, on their own, students initiated the use of the hundreds boards when they were finding greatest common factors and least common multiples and the fraction bars when they were finding equivalent fractions.

The AO teachers who did not use manipulatives prior to the project did not see an increase in manipulative use by their students during the free access period. On the other hand, the $\mathrm{CO}$ teachers who had used the manipulatives frequently prior to the project continued to use the manipulatives during the free access period. Therefore, the spontaneous use of the manipulatives by students during the free access period appeared to be related to the frequency with which their teachers used the manipulatives prior to free access rather than to the control or autonomy orientation of the teacher.

\section{New "Roles"}

In addition to a change in the seating arrangements and interactions among students and the teachers, some individuals also took on new roles during free access. For example, 3 teachers in the $\mathrm{CO}$ group (Andrea, Carol, and Elise) assigned some of their students as group leaders during mathematics lessons. During one observation, Andrea sent a student from the Period 3 class to locate a group leader from the Period 2 class because the container was missing one item. In Andrea's, Carol's, and Elise's classes students distributed and collected the container for the group and made sure all of the contents were there for the next class. Some of the students took this role very seriously and would not allow other students to obtain any of the materials in the containers, even during the portions of the lessons when students were permitted to use the manipulatives. One teacher had to explain to the group leaders that each student in the group was permitted to have free access to the materials. "They were being control freaks with the manipulatives," Andrea noted in one interview (I3). In this case, as the teacher's control decreased, the student leader control increased.

Students were assigned as group leaders in three classrooms and were observed in the role of peer tutors in four classrooms. For example, in one lesson in which students were learning to subtract mixed numerals, Carol reported, "I had these two kids that were so patient and they taught their whole group how to subtract mixed numerals with pattern blocks....I just loved seeing that. That was a little surprising, how patient and step-by-step they were" (I3). Students 
were observed spontaneously using pattern blocks to explain concepts to their peers (Carol, O4).

In some cases, students used manipulatives to perform different solution methods than their teachers. In Julie's class, students were observed using a tangram piece to find the areas of figures. When one student selected additional tangram pieces from the container to lay on the figure to find the measurement, Julie told the student to put the pieces back into the container and use only one tangram piece for the measurement. In this case, the student's original selection and solution strategy was appropriate for the task and would have aided the student in figuring out how many total tangram pieces fit inside the figure. Instead, the student had to trace the one tangram piece over and over again to find the total number of tangram pieces that fit inside the figure. The student's strategy would have been quite efficient, because the tangram pieces could have been manipulated and arranged on the figure until they were able to fit inside the boundary. Following the teacher's instructions, the student had to trace and erase lines until he found the arrangement that fit the figure.

During open-ended problem solving lessons, students were able to use a variety of manipulatives to assist them in their mathematical thinking. For example, in the "Restaurant Problem," in which students selected the number of tables to use for a banquet, and the "Barnyard Problem," in which students determined the number of cows and chickens in the barnyard given the number of legs, students used the block-like materials (including color tiles, centimeter cubes, and snap cubes) to model and solve problems. In Brenda's class students were observed using color tiles, centimeter cubes, and snap cubes to arrive at their answers and explain these answers to their peers (O3). During the follow-up interview, Brenda reported, "I saw one group, they were using the snap cubes. Then another group, they were using the centimeter cubes" (I3). Other teachers made these observations, especially when their students were engaged in group activities.

An exception. Spontaneous use of manipulatives was observed in 9 of the 10 classrooms. Elise's class was the exception. Her students used the manipulatives only when she directed them to do so. This was evident in all four observations. Elise was also very clear to her students that using the manipulatives would not disrupt her class (I3). Students in her classroom did not spontaneously use any of the manipulatives during observations, and in her interviews, Elise's comments supported this observation. The only student response she reported occurred when she first put manipulatives out in her classroom, when interested students asked her what was in the containers and what manipulatives would be available to them. This initial interest was the only reference students made to the manipulatives during free access. Elise had predicted that her students would not use any of the manipulatives and the students lived up to her expectations. She explained this by saying, "I don't know if they were apprehensive because of how my class is structured" (Elise, I3).

\section{Discussion}

\section{The Conflict of Shifting Sets, Scripts, and Roles}

The teachers in this study were already confident in their mathematics teaching abilities. By attending the summer institute, they also demonstrated their willingness to continue their professional growth in mathematics teaching.

Sets. The first observable change during free access was in the "set" — that is, the mathematics environment in each classroom. For these teachers, the familiar set shifted to accommodate access to the manipulatives. The new set was one in which students exercised some choice and autonomy in their selection of materials. This set was often very different from the one in which the teacher had total control of the materials.

As they anticipated how giving students choice would impact their mathematics instruction, some teachers acted on their concerns by preemptively restructuring the set. Some teachers, like Andrea, moved their students' desks from rows to groups of four to accommodate using the containers of materials in groups during free access. Although she made the choice to rearrange her classroom, her move suggests that she foresaw the inherent conflict between her original set and the new one. However, 3 of the teachers chose to keep student desks in rows throughout free access and placed containers on the floor, consequently limiting students' access to the manipulatives. These teachers seemed either unwilling to give up the old set or unaware of the restrictions it placed on students' accessing the materials.

Scripts. The next change that took place was in the "script" - that is, the verbalizations and actions during the lessons. In some cases, students took on the "teacher script" by tutoring their peers during work time, admonishing peers for inappropriate use of the materials, or controlling other students' access to the tools.

When students were given choice, teachers found themselves posting rules and lists on containers and assigning team leaders. The precarious nature of the new situation may have appeared threatening, and they 
sought to control it by scripting actions for themselves and for their students.

Roles. There was a new dynamic in the "roles" of teachers and students — that is, each individual's responsibility for participation in the classroom. Mathematics teachers have known their roles for years: They teach the rules and procedures of mathematics (Stigler \& Hiebert, 1999). Students are familiar with their roles of following and learning the rules of mathematics. Giving students choice enabled these teachers and students to take on different roles, and the parameters of these new roles were not clearly defined. In these instances, teachers continually reaffirmed their roles by subtly and overtly exerting control and limiting students' choices.

The role of controlling all aspects of learning is a familiar role for the teacher. Using free access can be a threat to this familiar role and may throw teachers' classroom management systems out of balance, forcing teachers to find new ways to reestablish their roles (as observed when teachers posted rules on the containers). During interviews, teachers verbalized some apprehension about what their new roles would be in an environment where students were given more choice. In addition, students indicated some confusion about their new roles in the free access environment. For example, some students themselves became controlling of the materials, others thought it was a trick, and some became teachers for their peers. In the classrooms where students were assigned as group leaders, being the student group leader in charge of the manipulatives may be viewed as teachers sharing their role, or as an additional level in the hierarchy of control.

\section{Controlling Choice}

Essentially all classroom teaching and learning involves the negotiation of various aspects of control. For some teachers, decisions to use or not to use manipulatives are based on the amount of control they believe they will be able to maintain in their classrooms. For others, the decision to use manipulatives is based on their perception of the usefulness of each individual manipulative. (For example, while mathematics teachers may see a protractor as a necessary tool for measuring angles, they may not view pattern blocks or fraction bars as important for understanding operations with fractions.)

Many of the teachers in this study systematically used control strategies (as described by Brophy \& Good, 1986), both positively and negatively. Negative control strategies can undermine student choice and discourage students' free access to and use of materi- als when these tools could assist with conceptual development. Such strategies limit student thinking to the teacher's line of thinking, as in the case of Julie when she insisted on the student solving the area problem using her tangram methods. Conversely, positive control strategies can be used to demonstrate and promote the effective use of appropriate mathematical tools. By focusing play and investigation, these strategies help promote the beneficial aspects of exploration and students' spontaneous use of materials. Control strategies, when implemented positively, allow and encourage diversity in problem solving and responses. In this study, teachers used positive control strategies to focus their students' attention during lessons. They often demonstrated concepts first, then gave students manipulatives with an assigned task and a stated purpose.

Brophy and Good (1986) reported the existence of a curvilinear relationship between the control of behavior during learning tasks and student achievement; in essence, too little or too much control decreases student achievement. In some classes, teachers anticipated student behavior problems that might occur when the manipulatives were used and structured their lessons to avoid these occurrences wherever possible. The lesson structures of other teachers avoided the challenges of tool use altogether, as in Elise's classroom where students did not use the manipulatives except when directed by the teacher.

\section{Student Choice}

Having the manipulatives available at student desks during free access gave the students something they had rarely experienced before with these materialstime and choice. Students had time to explore the uses of the tools, time to investigate how these materials might be used and manipulated, time to examine attributes of the materials, and time to construct their own understanding of mathematical ideas. They also had the opportunity to choose mathematical tools for their solution routes. Having the materials available at their desks may allow students to devise their own solution strategies and promote autonomous thinking and confidence in learning mathematics. Typically, when students do not understand a concept in mathematics, they can raise their hands and have the teacher stop class to focus attention on them, they can ask a peer, or they can stay after class to ask the teacher. A final option many students choose is to remain silent so they do not call attention to themselves. Choosing not to call attention to themselves can be particularly true of students in the middle grades. Curiously enough, once these students realized their freedom to choose, they spontaneously 
scripted their own participation in the mathematics lessons. Similar to the results found by Hirschhorn and Senk (1992), students in these classrooms started with overuse of the mathematics tools and moved to more appropriate use over time.

Although some initial inappropriate behaviors were observed, students became more selective in their use of the materials and used the manipulatives to mediate their own learning or to explain their thinking in peer tutoring situations. There was also diversity in the ways different students used manipulatives to solve similar problems, as in the observations of the problem solving activities in Brenda's and Carol's classrooms. These interactions resulted in more discussions among students and, as teachers reported, more student talk about mathematics.

Some teachers exhibited control of the manipulatives by restricting access to the materials, limiting use during instruction, placing lists on containers and classrooms walls, assigning group leaders for the purpose of monitoring the materials, and removing the manipulatives based on student behaviors. When teachers relinquished control of the tools, some students were empowered to take responsibility for their own learning (as in Julie's classroom when she responded to the student who suggested using the geoboards to solve a problem). Because manipulative use is often considered enjoyable, or "fun," for teachers and students, many teachers use manipulatives as a reward for appropriate student behavior (Moyer, 2001).

While teachers may dismiss playing with manipulatives as mere enjoyment, this kind of tinkering or messing about is described by some researchers as a characteristic of informal learning that can lead to tool expertise (Bagley \& Chaille, 1996; Thorne, 1993). It is also possible that some students (regardless of prior experiences or achievement) take great pleasure in tinkering with the materials in creative and inventive ways. In a study of 400 eminent adults who had made significant achievements, Goertzel and Goertzel (1962) reported that one common characteristic in the lives of these famous people was a history of tinkering with materials. A number of students in the present study were observed spontaneously using the materials in inventive ways. It is interesting to consider whether or not mathematics classrooms foster the types of thinking in students that lead to this spontaneity of invention.

Limitations. The results of this study should be interpreted with care, as the study is limited to the 10 teachers who voluntarily completed a 2-week professional development institute in middle grades mathematics. These teachers were, by definition, interested in their professional growth and were not representative of all middle grades mathematics teachers. A randomly selected teacher group from the general population may have yielded much different results. Another limitation of the study is the number of years of teaching experience of the two groups and the control versus autonomy orientations of the teachers. Determining whether a particular behavior or verbalization might be attributed to the control orientation of the teacher or to the teacher's years of teaching experience is difficult. The results of this study are also limited by the interpretive frames of the researchers, who see value in students' use of tools in mathematics learning. A further limitation is that teacher and student control is tied to other aspects of personality, behavior, and beliefs.

\section{Conclusion}

This study examined teachers' and students' verbalizations and behaviors in middle grades classrooms, where manipulatives were used to support mathematics teaching and learning. Of particular interest in this study was how teachers and students renegotiated their roles as manipulatives were introduced and students were permitted free access to them. Ways that teachers control choice during mathematics instruction calls into question the ownership of strategies, ideas, and processes, requiring a self-examination of the kind of thinking teachers foster in mathematics classrooms.

Promoting autonomous thinking in students requires a shift in the mathematics teaching and learning routine and a willingness to encourage students to think and make sense of mathematics for themselves. However, buying a box of manipulatives and allowing students free access is also not the answer. Promoting mathematics learning environments where students construct meaning requires major shifts in the sets, scripts, and roles of teachers and students. Allowing students some choice in their selection of mathematical tools is a minor step in encouraging responsibility for their own learning. For some teachers, providing manipulatives shifted control from control of the class to control of students' access to mathematics tools.

Teachers who view manipulatives as time wasting or secondary to the serious work of learning mathematics will inadvertently encourage their students to use these materials for play, rather than for mathematical learning or understanding. By demonstrating how to use the manipulatives as tools for better understanding, teachers open doors for many students who struggle with abstract symbols. Often this struggle can be 
minimized or avoided entirely by simply using different representations before using abstract symbols alone, thus giving students a firm conceptual base on which to build higher mathematical thinking. Communicating the value of representations and the importance of being able to move flexibly among different representational systems, including manipulatives, visual images, and abstract symbols, helps students develop a deeper understanding of mathematics.

In this study students began to see these materials as one of many tools in their mathematics environment and spontaneously and selectively used the materials effectively to mediate their learning. When supporting teachers in transitioning to environments in which students take a more active role in their own learning (NCTM, 2000), it may be important to provide multiple visions of teaching and learning mathematics that include the element of choice.

\section{References}

Bagley, D., \& Chaille, C. (1996). Transforming play: An analysis of first-, third-, and fifth-graders play. Journal of Research in Childhood Education, 10(2), 134-142.

Brophy, J., \& Good, T. (1986). Teacher behavior and student achievement. In M. Wittrock (Ed.), Handbook of research on teaching (3rd ed., pp. 328375). New York: Macmillan Publishers.

Cobb, P. (1994). Constructivism in mathematics and science education.Educational Researcher, 23(7), 4.

Cobb, P., \& Steffe, L. P. (1983). The constructivist researcher as teacher and model builder. Journal for Research in Mathematics Education, 14(2), 83-94.

Cobb, P., Yackel, E., \& Wood, T. (1992). A constructivist alternative to the representational view of mind in mathematics education. Journal for Research in Mathematics Education, 23(1), 2-33.

Deci, E. L., \& Ryan, R. M. (1987). The support of autonomy and the control of behavior. Journal of Personality and Social Psychology, 53(6), 10241037.

Deci, E. L., Schwartz, A. J., Sheinman, L., \& Ryan, R. M. (1981). An instrument to assess adults' orientations toward control versus autonomy with children:Reflections on intrinsic motivation and perceived competence. Journal of Educational Psychology, 73(5), 642-650.

Deci, E. L., Spiegel, N. H., Ryan, R. M., Koestner, R., \& Kauffman, M. (1982). The effects of performance standards on teaching styles: The behavior of controlling teachers. Journal of Educational Psychology, 74, 852-859.

Driscoll, M. J. (1983). Research within reach: Elementary school mathematics and reading. St. Louis: CEMREL, Inc.

Goertzel, V., \& Goertzel, M. (1962). Cradles of eminence. Boston, MA: Little, Brown.

Greabell, L.C. (1978). The effect of stimuli input on the acquisition of introductory geometry concepts by elementary school children. School Science and Mathematics, 78, 320-326.

Hirschhorn, D. B. \& Senk, S. (1992). Calculators in the UCSMP curriculum for grades 7 and 8. In J. Fey \& C. Hirsch (Eds.), Calculators in mathematics education, NCTM yearbook (pp. 79-90). Reston, VA: National Council of Teacher of Mathematics.

LeCompte, M. D., Preissle, J., \& Tesch, R. (1993). Ethnography and qualitative design in educational research (2nd ed.). San Diego, CA: Academic Press.

Moyer, P. S. (2001). Are we having fun yet? How teachers use manipulatives to teach mathematics. Educational Studies in Mathematics, 47(2), 175-197.

National Council of Teacher of Mathematics. (2000). Principles and standards for school mathematics. Reston, VA: Author.

National Research Council. (2001). Adding it up: Helping children learn mathematics. J. Kilpatrick, J. Swafford, and B. Findell (Eds.). Mathematics Learning Study Committee, Center for Education, Division of Behavioral and Social Sciences and Education. Washington, DC: National Academy Press.

Parham, J. L. (1983). A meta-analysis of the use of manipulative materials and student achievement in elementary school mathematics. Dissertation Abstracts International, 44A, 96.

Peterson, P. L., Fennema, E., \& Carpenter, T. (1989). Using knowledge of how students think about mathematics. Educational Leadership, 46, 42-46.

Raphael,D., \& Wahlstrom, M. (1989). The influence of instructional aids on mathematics achievement. Journal for Research in Mathematics Education, 20(2), 173-190.

Reeve, J., Bolt, E., \& Cai, Y. (1999). Autonomysupportive teachers: How they teach and motivate students. Journal of Educational Psychology, 91(3), 537-548.

Sowell, E. J. (1989). Effects of manipulative materials in mathematics instruction. Journal for Research in Mathematics Education, 20(5), 498505.

Stigler, J. W., \& Hiebert, J. (1999). The teaching gap. New York: The Free Press. 
Suydam, M.N.(1985).Researchon instructional materials for mathematics. Columbus, OH: ERIC Clearinghouse for Science, Mathematics, and Environmental Education. (ERIC Document Reproduction Service No. 276 569).

Suydam, M. N. (1986). Manipulative materials and achievement. Arithmetic Teacher, 33(6), 10, 32.

Thorne, B. (1993). Gender play: Girls and boys in school. New Brunswick, NJ: Rutgers University Press.

Yackel, E., \& Cobb, P. (1996). Sociomathematical norms, argumentation, and autonomy in mathematics. Journal for Research in Mathematics Education, 27(4), 458-477.
Editors' Note: Correspondence concerning this article should be addressed to Patricia S. Moyer, George Mason University, 14337 Uniform Drive, Centreville, VA 20121.

Electronic mail may be sent via Internet to pmoyer@gmu.edu 